\title{
Comparison of Antibiogram Results of Two Types of Antibiotic Discs and Validation by E.test Method on Bacteria with High Antibiotic Resistance Patterns
}

\author{
Hamid Reza Ghasemi Basir ${ }^{1}$ (D), Fariba Keramat ${ }^{2}$, Abbas Moradi ${ }^{3}$, Zahra Khani ${ }^{4}$, Ali \\ Saadatmand $^{5 * \text { iD }}$ \\ ${ }^{I}$ Associate Professor, Department of Pathology, School of Medicine, Hamadan University of Medical Sciences, \\ Hamadan, Iran \\ 2 Professor, Brucellosis Research Center, Hamadan University of Medical Sciences, Hamadan, Iran \\ ${ }^{3}$ Instractor, Department of Community Medicine, School of Medicine, Hamadan University of Medical Sciences, \\ Hamadan, Iran \\ ${ }^{4}$ General Practitioner, Hamadan University of Medical Sciences, Hamadan, Iran \\ ${ }^{5}$ MSc in Microbiology, Brucellosis Research Center, Hamadan University of Medical Sciences, Hamadan, Iran
}

* Corresponding Author: Ali Saadatmand, Brucellosis Research Center, Hamadan University of Medical Sciences, Hamadan, Iran.Email: Ali.s_umsha@yahoo.com

Received: 29.12 .2020

Accepted: 13.04.2021

How to Cite this Article: Ghasemi Basir HR, Keramat F, Moradi A, Khani Z, Saadatmand A. Comparison of Antibiogram Results of Two Types of Antibiotic Discs and Validation by E.test Method on Bacteria with High Antibiotic Resistance Patterns. Avicenna J Clin Med. 2021; 28(1): 59-65. DOI: 10.52547/ajcm.28.1.59

\section{Abstract}

Background and Objective: The increased resistance of microorganisms to common antibiotics is one of the major therapeutic challenges for patients. The present study aimed to compare the antibiogram results of two types of antibiotic discs and validate them by the Epsilometer test (E-test) method on bacteria with high antibiotic resistance patterns.

Materials and Methods: This descriptive-analytical study was performed by the census method on 176 patients admitted to different wards of Sina Hospital in Hamadan from March 2016 to March 2019. The patients entered the study with a positive culture result and underwent the antibiogram using two types of discs. Following that, validation was performed by the Etest method in cases with significant differences. Finally, the results were described and analyzed in SPSS software (version 16) at a 95\% confidence interval.

Results: Out of 176 patients, 80 (45.4\%) and 96 (54.5\%) cases were male and female, respectively. The mean age of patients was reported as $62.44 . \pm 20.47$ years. The most common culture sites were trachea $(45.5 \%)$ and urine $(42.6 \%)$, and the most common cultured microorganisms were E.coli (33.5\%), Klebsiella (29.5\%), and Acinetobacter (18.8\%). The highest correlation coefficients of the results by disk diffusion method were observed in levofloxacin $(\mathrm{r}=1.00)$, piperacillin $(\mathrm{r}=0.917)$, ciprofloxacin $(\mathrm{r}=0.907)$, cotrimoxazole $(\mathrm{r}=0.904)$. On the other hand, the lowest correlation coefficients were related to imipenem $(\mathrm{r}=0.634)$, cefoxitin $(\mathrm{r}=0.556)$, and ceftriaxone $(\mathrm{r}=0.552)$.

Conclusion: As evidenced by the obtained results, significant differences were detected between the results of antibiogram in Iranian and imported disks. After verification and validation using E.test, the percentage of agreement was in favor of imported disks.

Keywords: Antibiogram, Disk Diffusion, E.Test 
do): $10.52547 /$ ajcm.28.1.59

\title{
مقايسه نتايج آنتىبيو كرام دو نوع ديسك آنتىبيوتيكى و صحتسنجى با روش E.test بر باكترىهاى داراى الكوى مقاومت آنتىبيوتيكى زياد
}

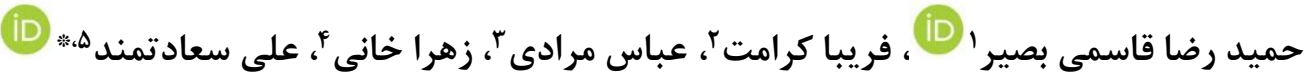

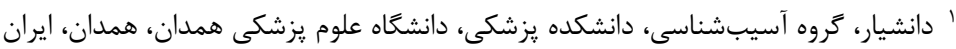

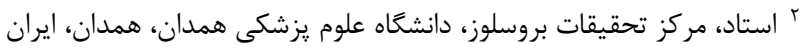

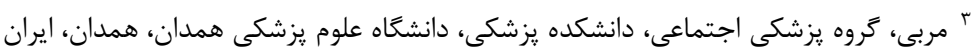

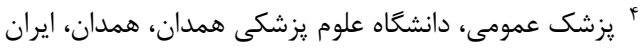

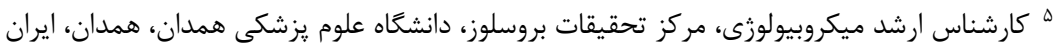

* نويسنده مسئول: على سعادتمند، مركز تحقيقات بروسلوز، دانشكاه علوم يزشكى همدان، همدان، ايران. ايميل: Ali.s_umsha@yahoo.com

\begin{tabular}{|c|c|}
\hline 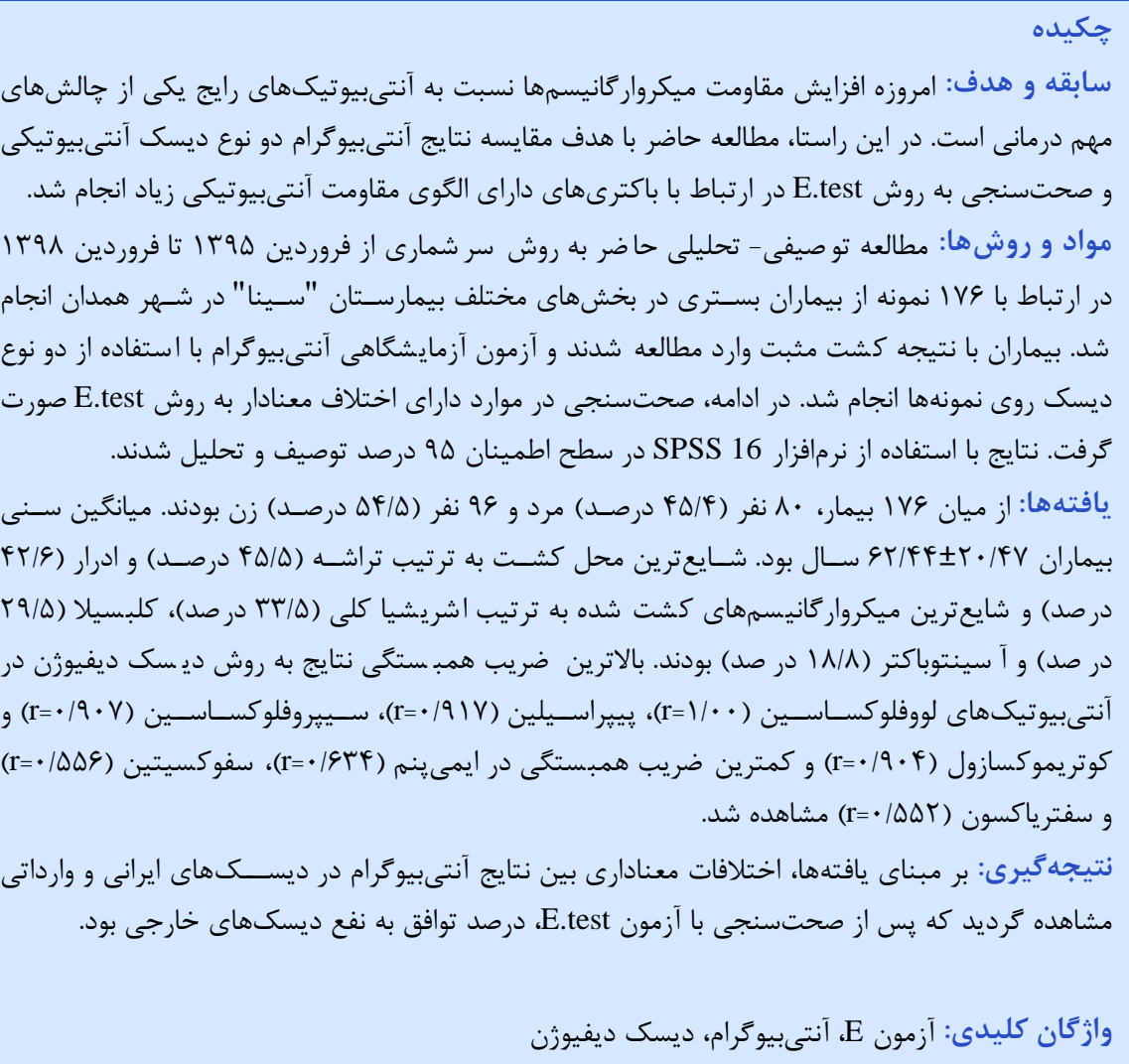 & 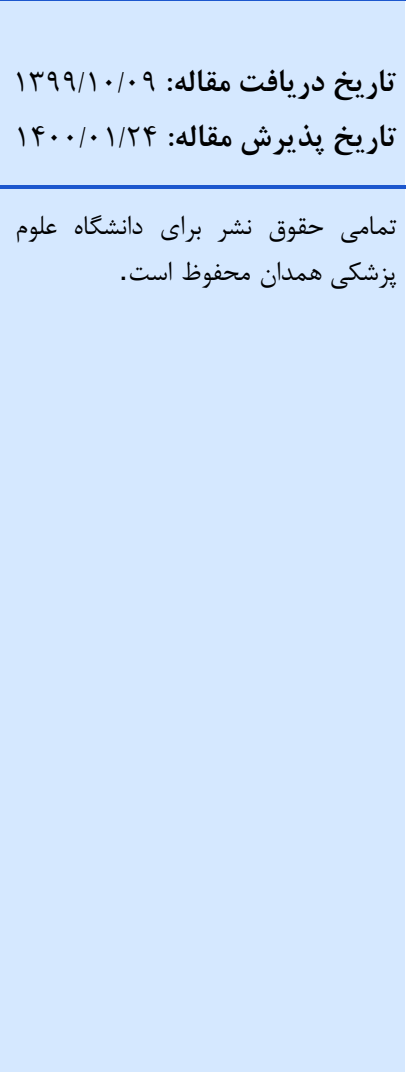 \\
\hline
\end{tabular}

مقلدمه

و به دنبال آن نسلهاى جديد مقاوم به وجود مى آيند كه باعث

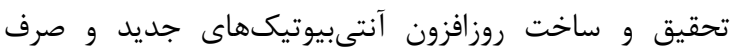
هزينههاى بالا در اين زمينه مى

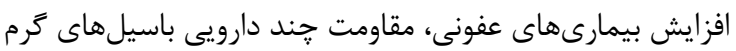

$$
\text { منفى است [9. V. V. }
$$

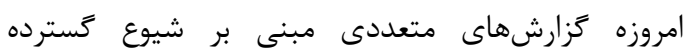

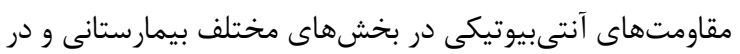

باكترىها ممكن است بر اثر عواملى از جمله مصرف بعرويه

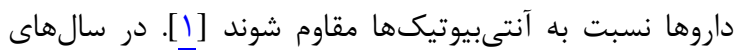

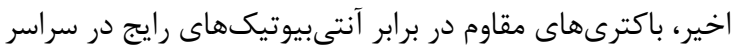

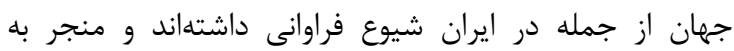

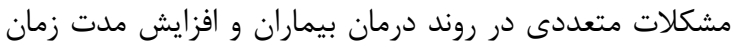

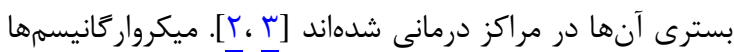

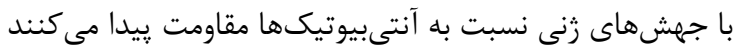


بسترى در بخشهاى مختلف بيمارستان سينا به آزمايشعاه اين

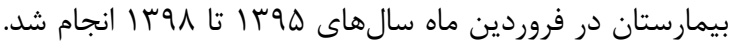

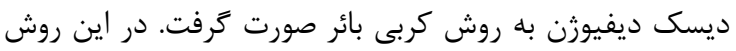

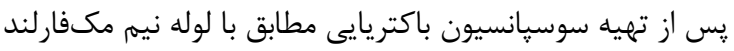

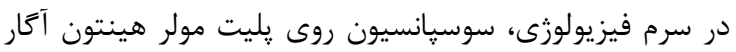

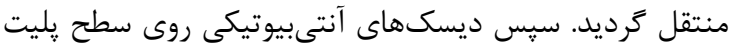

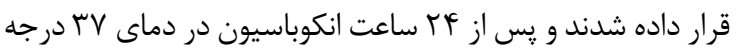

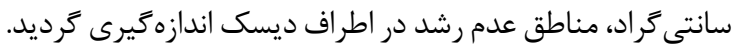

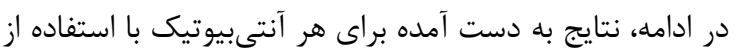

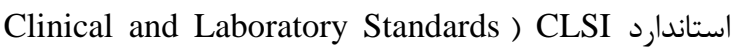
(Institute

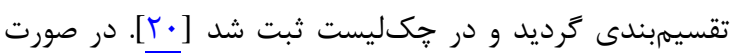

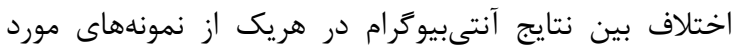

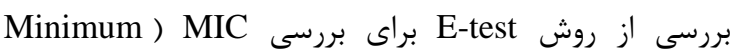
(Inhibitory Concentration صحتسنجى آزمايش ديسك ديفيوزن براى مقايسه اين دو برند

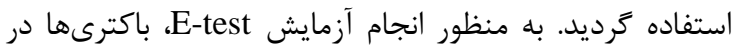

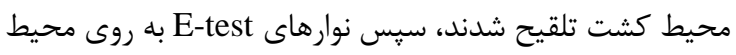

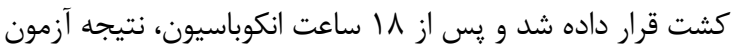
از جهت بالاى نوار به طرف يايين نوار به منظور تعيين MIC خواند إنده

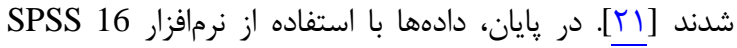

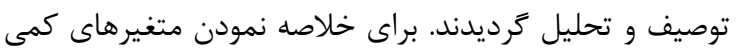

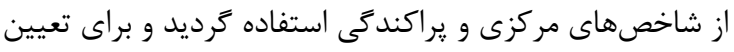

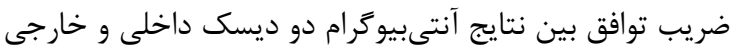

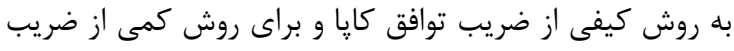

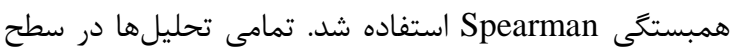
اطمينان ه9 درصد صورت گرفت و سطح معنادارى كمتر از هـ • • . در نظر گرفته شد.

\section{يافته ها}

به منظور انجام اين مطالعه، IV9 آزمايش كشت و و

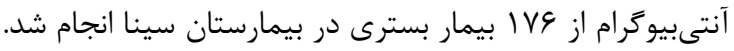

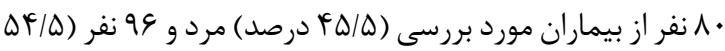
درصد) زن بودند. ميانگين و انحراف معيار سنى بيمان برداران

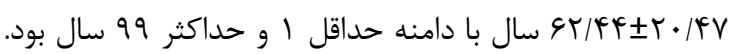

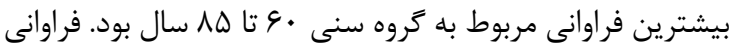

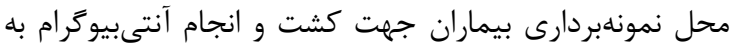

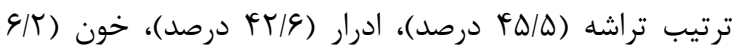

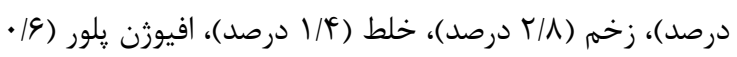

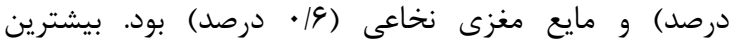
باكترىهاى كشت داده شده به ترتيب اشريشيا كلى (ه/برس

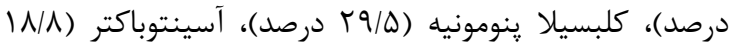

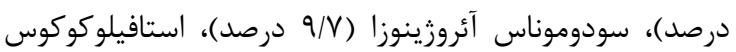

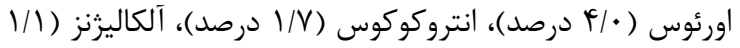

سطح جامعه وجود دارد [1،،9] كه اين امر غالباً مىتواند به دليل تجويز نادرست و بىرويه داروهاى آنتىبيوتيكى و يا مصرف خودسرانه آنها باشد [ن • (1].

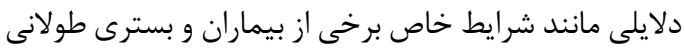

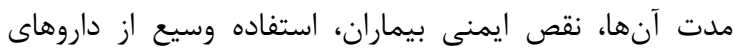

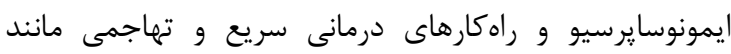

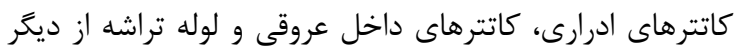

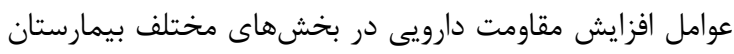

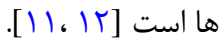
باكترىهاى ايجادكننده عفونت غالباً الكوى مقاومت دارويى الري كستردهاى را از خود نشان داده و سبب افزايش مرى ونى و مير

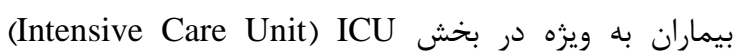
9.

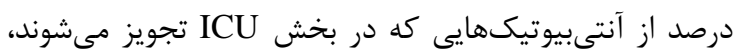

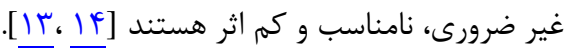

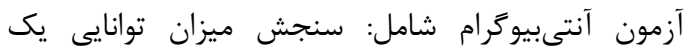

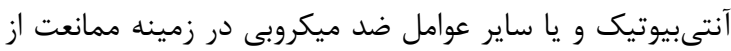

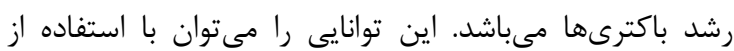

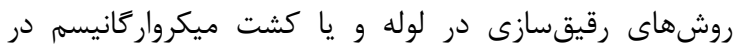

يليتهاى كشت ميكروبى اندازهيرى نمود [هارئ.

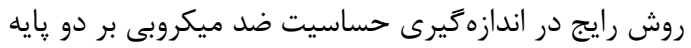

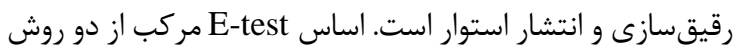

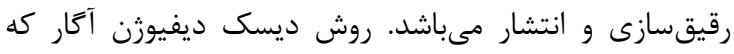

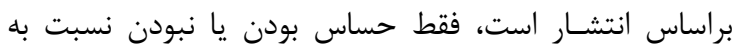

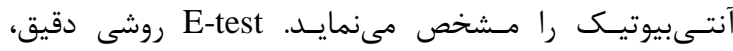
حساس و ويزه در نمونههاى مقاوم به ديسكهاى آنتىبيوتيك رئي

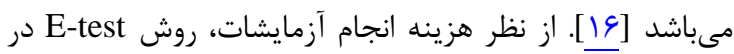

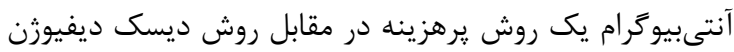

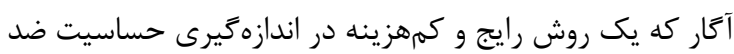

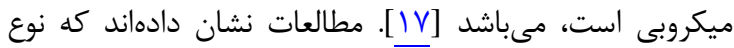

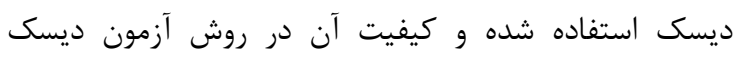

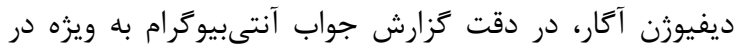

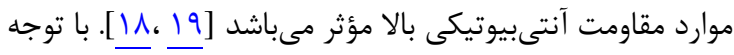
به مطالب بيان شده، مطالعه حاضر با هدف مقايسه نتايج آنتىبيوكرام دو نوع ديسك آنتىبيوتيكى پادتن طب و و

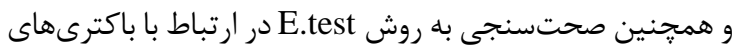
داراى الكوى مقاومت آنتىبيوتيكى زياد انجام شد. ردئ

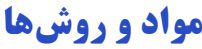

اين مطالعه به صورت توصيفى- مقطعى به منظور مقايسه

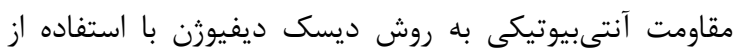

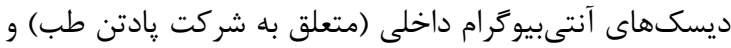

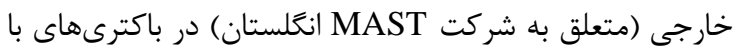
مقاومت آنتىبيوتيكى زياد در نمونههاى ارسال شده از بئ بيماران 
(r=•/9 |V) و كمترين ضريب همبستغى مربوط به ايمىينه

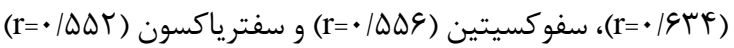
مىباشد. در اين مطالعه بيشترين شيوع باكترىهاى كشت داده شده

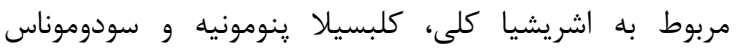

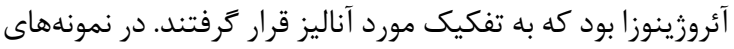
كشت مثبت اشريشيا كلى در هر دو روش كمى و كيفى، بيشترين

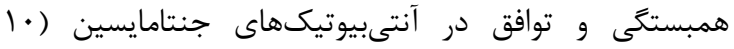
ميلى گرم) و سييروفلو كساسين (ل ميلى گرم) مشاهده شد (بالاى

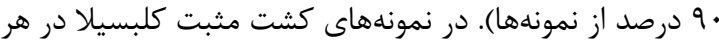
دو روش كمى و كيفى نيز بيشترين همبستخى و توافق در تمام

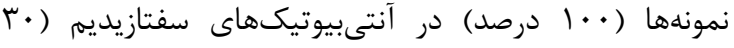

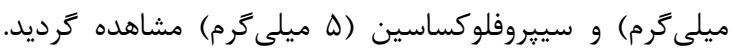

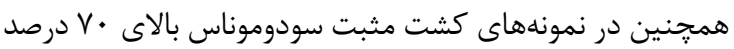

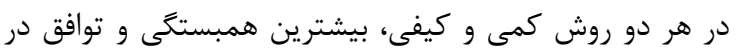

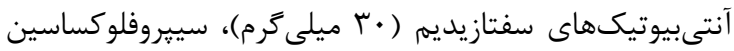

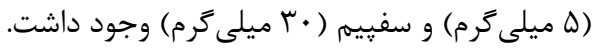

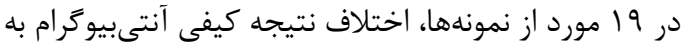
روش ديسك ديفيوزن بين ديسك MAST و پادتن، آزمايش به ديه

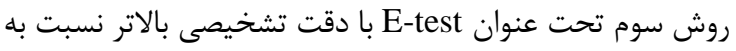
روش ديسك ديفيوزن به منظور محاسبه MIC انجام شد تا بتوان بين اين دو ديسك ايرانى و خارجى به دقت قضاوت كرد.

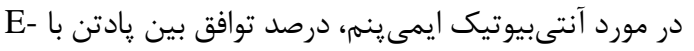
test از نظر نتيجه آنتىبيوكرام با يكديگر توافق داشتند. در E-test،
درصد)، استنوتروفوموناس ( / / درصد) و ينوموكوك (9/ • درصد)

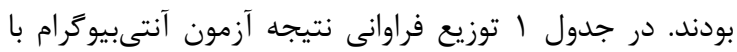

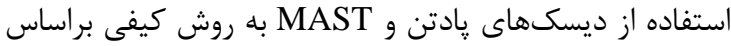

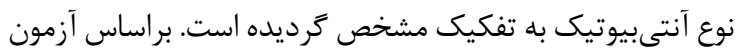

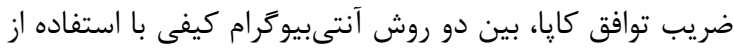

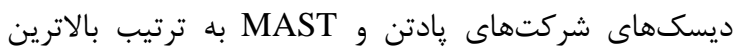
ضريب توافق مربوط به سه آنتىبيوتيك سييروفلوكساسين

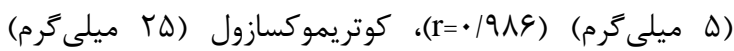
(r=•|AFA)

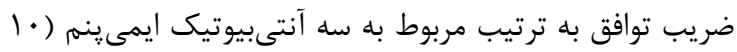
ميلى

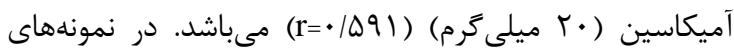

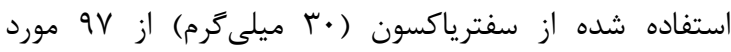

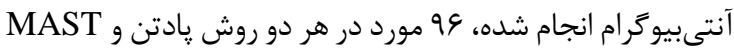
مقاوم بودند و تنها در يك نمونه، MAST حساس و و يادتن مقاوم

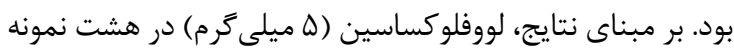

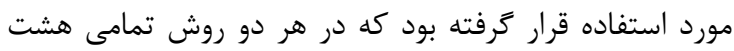

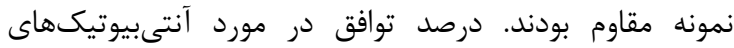

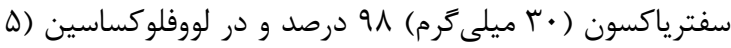
ميلى

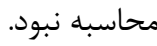

در جدول ا توزيع فراوانى ضريب همبستخى Spearman

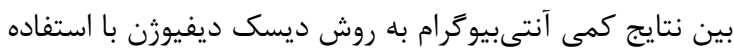

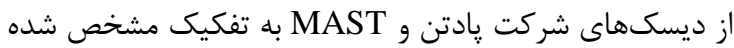
است. بالاترين ضريب همبستخى نتايج به روش ديسك ديفيوزن نئن

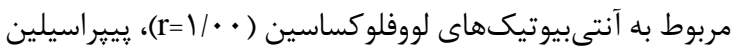

جدول (: توزيع فراوانى ضريب همبستكى Spearman بين نتايج كمى آنتىبيوكرام (ميلىمتر) به روش ديسك ديفيوزن با استفاده از ديسكهاى شركت MAST

\begin{tabular}{|c|c|c|c|}
\hline سطح معنادارى & ضر يب همبستخى & 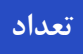 & آنتىبيوتيك \\
\hline$<\cdot / \cdot \cdot 1$ & $1 / \cdots$ & $\wedge$ & لووفلوكساسين (ه ميلى ترم) \\
\hline$<\cdot / \cdot \bullet 1$ & $.191 \mathrm{~V}$ & VV & يِيبراسيلين (•|l ميلى \\
\hline$<\cdot / \cdot \cdot 1$ & $\cdot 19 \cdot V$ & $|9|$ & سيبروفلوكساسين (ه ميلى گرم) \\
\hline$<\cdot / \cdot \cdot 1$ & $\cdot / 9 \cdot 4$ & $\Delta 9$ & كوتريموكسازول (ه ميلى \\
\hline$<\cdot 1 \cdot \cdot 1$ & $\cdot / 191$ & $F \Delta$ & نيتروفور انتوئين (•+r ميلى \\
\hline$<\cdot 1 \cdot \cdot 1$ & $\cdot / \Lambda \mathrm{V}$ & 149 & جنتامايسين (•ا ميلى \\
\hline$<\cdot / \cdot \cdot 1$ & - IAfE & vr & آميكاسين (•r ميلى \\
\hline$\cdot / \cdot v$ & $\cdot / \vee \wedge 9$ & 1 . & ونكومايسين (•ب ميلى \\
\hline$<\cdot / \cdot \cdot 1$ & $\cdot / V \wedge F$ & $\Delta \cdot$ & آميى سيلين (• ب ميلى \\
\hline$<\cdot / \cdot \cdot 1$ & $\cdot / V \vee \Delta$ & $1 \cdots$ & مروينم (•ا ميلى كرم) \\
\hline$<\cdot / \cdot \cdot 1$ & $\cdot \ln$ & $v^{f}$ & سفتازيديم (•r ميلى \\
\hline$<\cdot / \cdot \cdot 1$ & $\cdot 19 \Delta \mid$ & 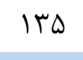 & سفييم (•r ميلى \\
\hline$<\cdot / \cdot \cdot 1$ & . IGTF & NF & ايمى ينهم (•اميلى \\
\hline$\cdot 1 \cdot 10$ & $\cdot / \Delta \Delta \varphi$ & $\wedge$ & سفوكسيتين (•r ميلى \\
\hline$<\cdot / \cdot \cdot 1$ & . IDQT & १V & سفتر ياكسون (•r ميلى \\
\hline
\end{tabular}




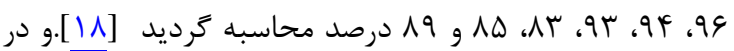
مقايسه با مطالعه حاضر، حجم نمونه در مجموع بيشتر بود؛ اما

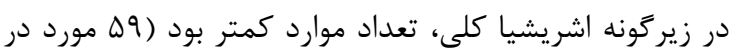

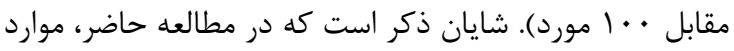

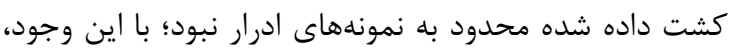

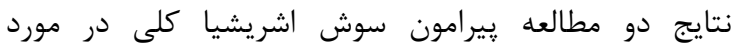

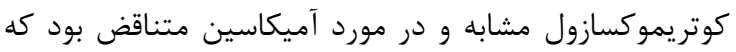

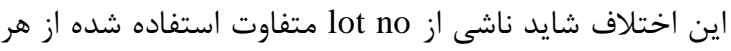
دو ديسك باشد.

در مطالعه صورت ترفته توسط فهيم زاد و همكاران با هدف

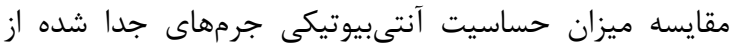

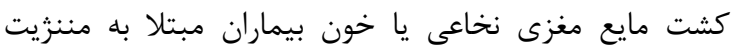

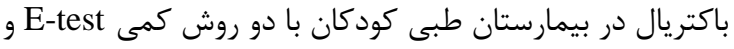

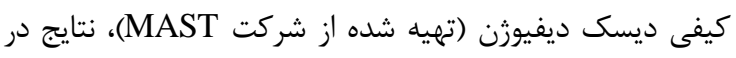

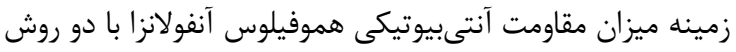

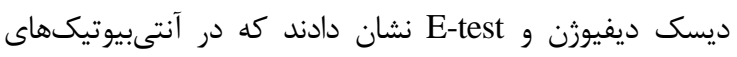

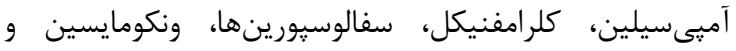
ريفاميين، بين دو روش آنتىبيوگرام ديسك ديفيوزن و

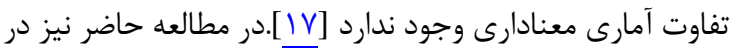

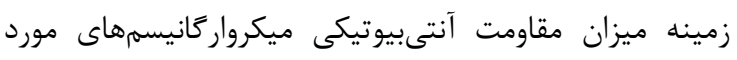
بررسى، درصد توافق بين نتايج E-test با نتايج كيفى ديسك انسئن

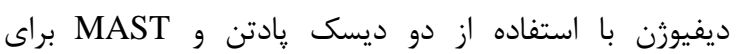
آنتىبيوتيك ايمىينه به ترتيب · • و و و

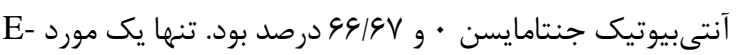

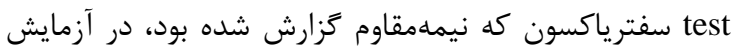

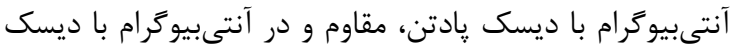

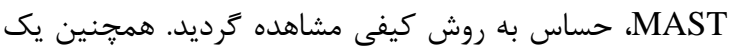

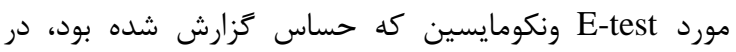

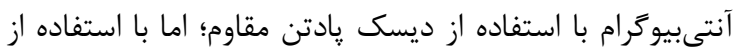

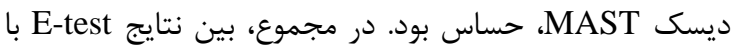

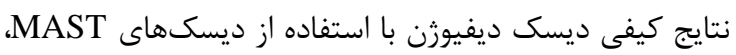

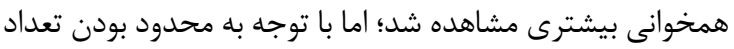

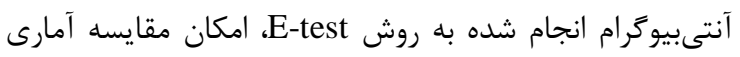
بين تمام نمونهها وجود نداشت. در مطالعه صورت گرفته توسط عرفانى و همكاران در زماند زمينه

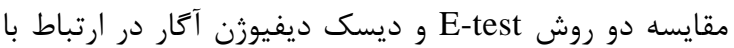

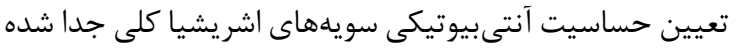

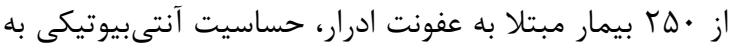
روش ديسك ديفيوزن آكار با استفاده از ديسكهاى آدائ ايرانى و

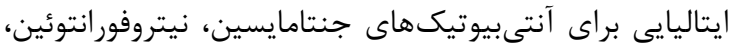

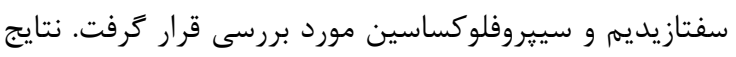

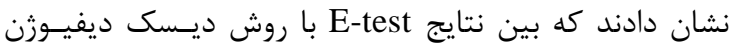

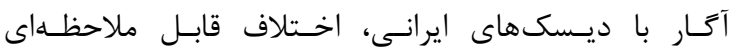

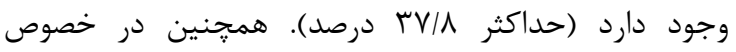

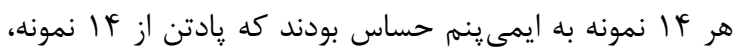

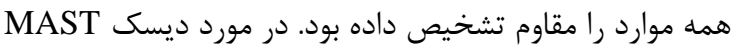

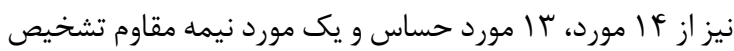

داده شد.

از سوى ديكر، در ارتباط با آنتىبيوتيك جنتامايسين براى

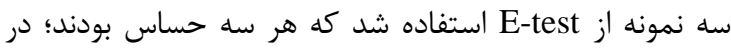

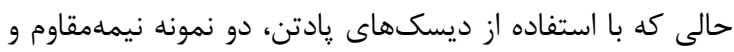

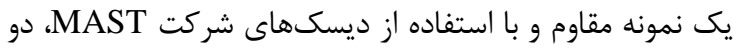
نمونه حساس و يك نمونه مقاوم تشخيص داده شدند. درصد

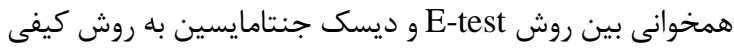

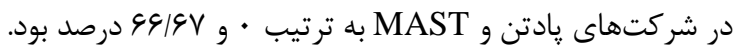

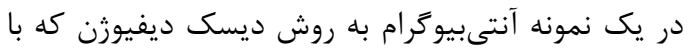

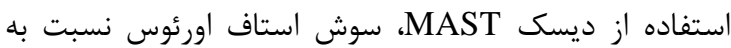

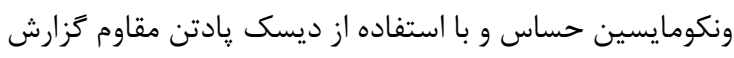

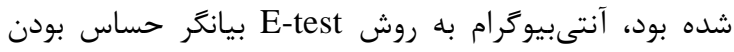

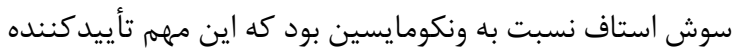

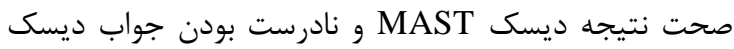

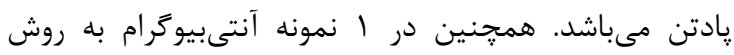

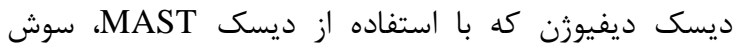

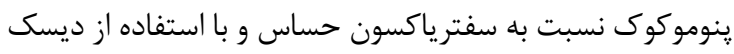

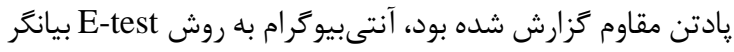

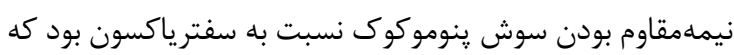

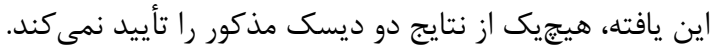

بحث در اين مطالعه بالاترين ضريب توافق به ترتيب مربوط به

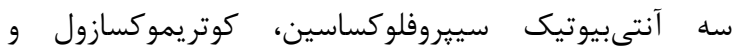

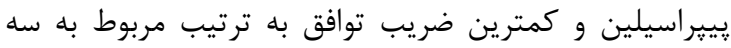

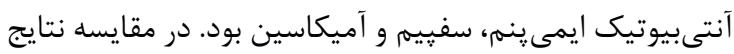

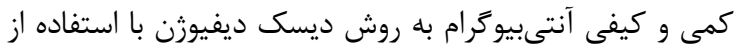

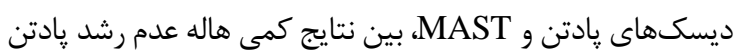

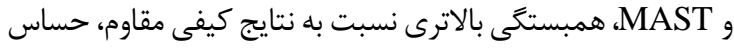
و حد واسط براساس جدول CLSI مشاهده شد. اين موضوع بيانكر آن است كه اختلافات عددى كم موجود بين دو ديسك در

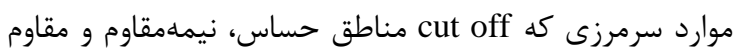

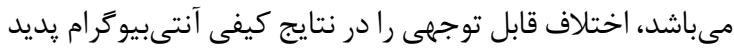
آورده و ضريب توافق كيفى را پايينتر ميى آورد.

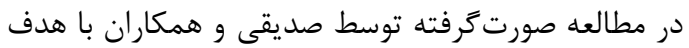

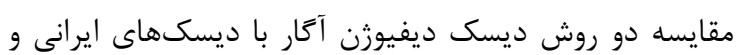

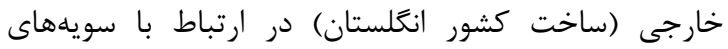

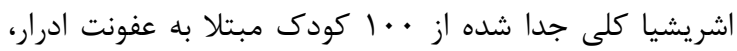

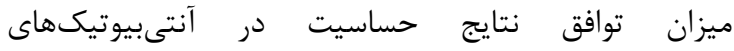
كوتريموكسازول، ناليديكسيك اسيد، سفترياكسون، آميكاسين، سفيكسيم و نيتروفورانتوئين در مطالعه مذكور به ترتيب معادل 


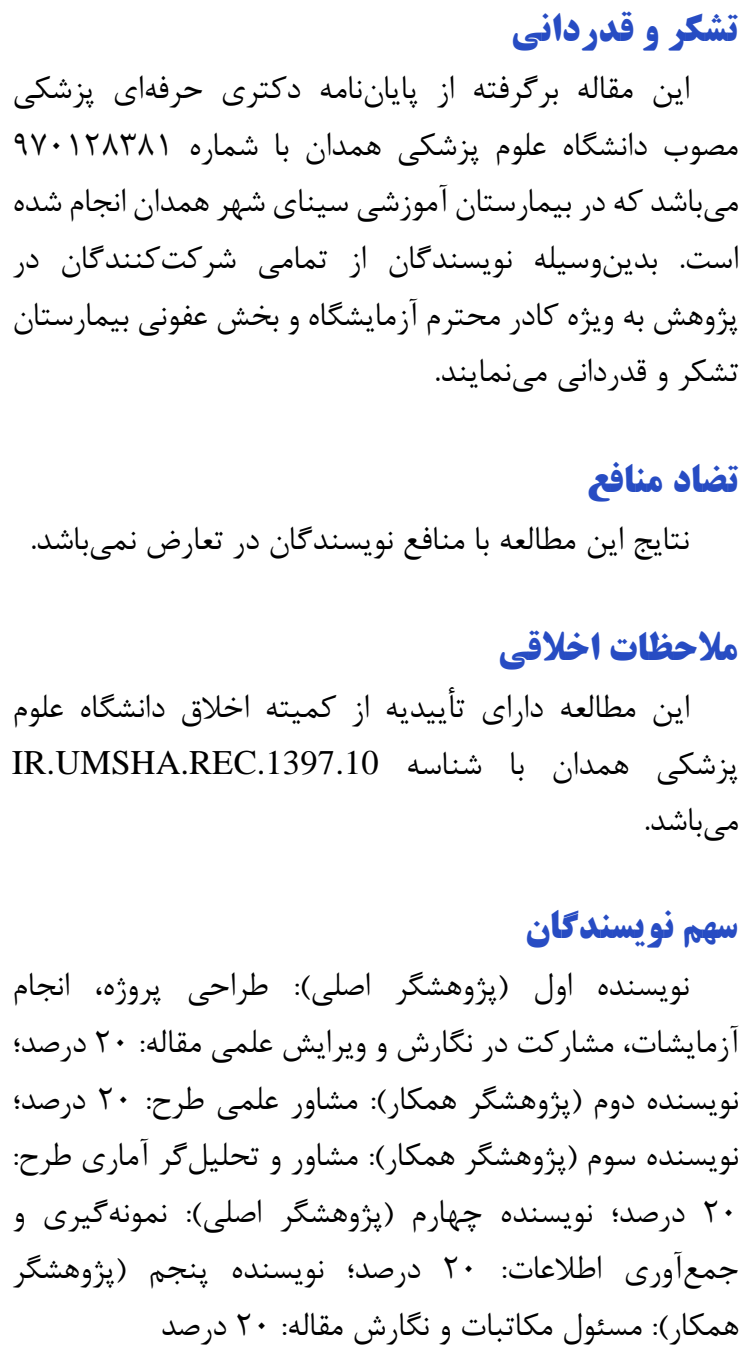

\section{ملاحظات اخلاقى}

اين مطالعه داراى تأييديه از كميته اخلاق دانشخاه علوم

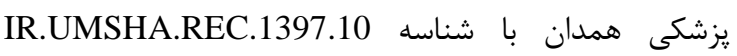
مىباشد.

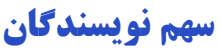

نويسنده اول (يزوهشخر اصلى): طراحى : يروزه، انجام

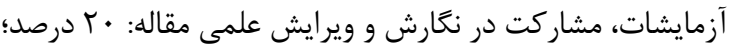

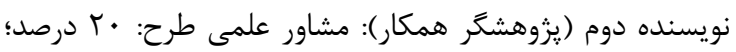

نويسنده سوم (يزوهشكر همكار): مشاور و تحليل

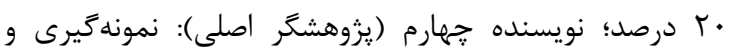

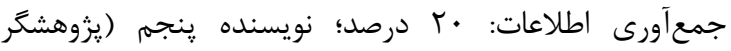

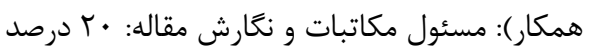

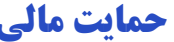

طرح حاضر از سوى معاونت تحقيقات و فناورى دانشكاه علوم

$$
\text { يزشكى همدان تأمين مالى شده است. }
$$

\section{REFERENCES}

1. Espinal MA, Laszlo A, Simonsen L, Boulahbal F, Kim SJ, Reniero A, et al. International union against tuberculosis and lung disease working group on anti-tuberculosis drug resistance surveillance. Global trends in resistance to antituberculosis drugs. N Engl J Med. 2001;344(17):1294-303. PMID: 11320389 DOI: 10.1056/NEJM200104263441706

2. Dadgari F, Ahmadi K, Mardani, Ramazan KA. Frequency and antibiotic resistance profile of bacteria isolated from the intensive care unit and General ward at a general hospital in Tehran. Ann Mil Health Sci Res. 2007;5(1):1155-64.

3. Keramat F, Homayoonfar S, Seif Rabiei M A, Abbasi K, Saadatmand A. Antibiotic resistance pattern of bacterial agents isolated from blood culture of patients with infective endocarditis. Tehran Univ Med J. 2019;77(4):240-5.

4. Van Hoek AH, Mevius D, Guerra B, Mullany P, Roberts AP, Aarts HJ. Acquired antibiotic resistance genes: an overview. Front Microbiol. 2011;2:203. PMID: 22046172 DOI: 10.3389/fmicb.2011.00203

5. Keshavarz-Hedayati S, Shapouri R, Habibollah-Pourzereshki $\mathrm{N}$, Bigverdi R, Peymani A. Molecular investigation of resistance to disinfectants in acinetobacter baumannii isolates collected from Qazvin hospitals, Iran (2017). J Qazvin Univ Med Sci. 2019;23(1):2-13. DOI: 10.32598/JQUMS.23.1.2

6. Girish N, Saileela K, Mohanty S. Extended Spectrum $\beta$ Lactamase producing Klebsiella pneumoniae and Escherichia
آنتىبيوتيك هاى سفتازيديم و جنتامايسين در مقايسه ديسك

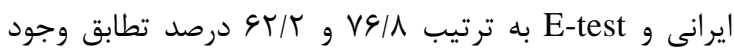
داشت؛ در حالى كه بين نتايج E-test با استفاده از ديسك ديفيوزن آتار و ديسكهاى ايتاليايى، اختلاف كمترى (حداكثر //1/ درصد) مشاهده شد [Yr] كه اين يافته همسو با نتايج مقايسه E-test و ديسكهاى يادتن و MAST در مطالعه حاضر بود؛ اما در مطالعه حاضر از 19 مورد E-test انجام شده در ارتباط با جهار آنتى بيوتيك ايمى ينهم، جنتامايسين، ونكومايسين و سفترياكسون، بين نتايج E-test با روش گيادتن و Mast به ترتيب • و ا N N درصد توافق وجود داشت. علت يايين بودن درصد مطابقت نتايج E-test با پادتن ممكن است ناشى از يايين بودن حجم نمونه در مطالعه حاضر نسبت به مطالعه عرفانى و همكاران (19 مورد در مقابل • • مورد) باشد. در مطالعه حاضر اختلاف فاحش در ززارش نتايج آنتىبيوگرام در ارتباط با آنتىبيوتيكهاى ايمى ينم، سفييهم و آميكاسين با استفاده از ديسكهاى يادتن و و

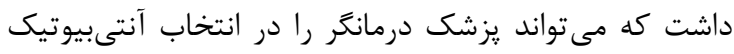
مناسب گمراه كرده و در موارد با مقاومت آنتىبيوتيكى بالا، روند درمان بيماران را دجار مشكل كند.

\section{تنيبجه تَيرى}

نتايج اين مطالعه نشان دادند كه در روش ديسك ديفيوزن، بين نتايج ديسكهاى آنتىبيوگرام داخلى و خارجى، در اكثر موارد كشت باكترىهاى با مقاومت آنتىبيوتيكى بالا، ضريب توافق و همبستخى قابل قبولى دارد؛ اما در برخى از موارد همجون ايمى ينهم، سفييم و آميكاسين، ضريب توافق يايين بود و نتايج صحيح مستلزم استفاده از ديسكهاى خارجى و يا روشهاى دقيقتر همجون E-test جهت تشخيص دقيق ميزان مقاومت آنتى بيوتيكى مى دياشد.

coli in neonatal intensive care unit. $J$ Bacteriol Parasitol. 2012;3(4):e1000141. DOI: 10.4172/2155-9597.1000141

7. Poulou A, Grivakou E, Vrioni G, Koumaki V, Pittaras T, Pournaras S, et al. Modified CLSI extended-spectrum $\beta$ lactamase (ESBL) confirmatory test for phenotypic detection of ESBLs among Enterobacteriaceae producing various $\beta$ lactamases. J Clinl Microbiol. 2014;52(5):1483-9. PMID: 24574283 DOI: $10.1128 /$ JCM.03361-13

8. Livermore DM. Of Pseudomonas, porins, pumps and carbapenems. J Antimicrobial Chemother. 2001;47(3):24750. PMID: 11222556 DOI: $10.1093 / \mathrm{jac} / 47.3 .247$

9. Majzoobi M M, Pirdehghan A, Rashidian Z, Saadatmand A. Etiologic agents and antibiotic resistance pattern of community- and hospital-acquired infections. Avicenna $J$ Clin Med. 2018;25(1):41-8. DOI: 10.21859/ajcm.25.1.41

10. Moayeri A, Aminshokravi F, Tavafian S, Moayeri A. Assessing related factors on the illicit use of medications in Abbas Abad city(Mazandaran): a cross sectional study. J Ilam Univ Med Sci. 2014;22(5):11-9.

11. Coia JE, Duckworth GJ, Edwards DI, Farrington M, Fry C, Humphreys H, et al. Guidelines for the control and prevention of Meticillin-Resistant Staphylococcus aureus (MRSA) in healthcare facilities. J Hosp Infect. 2006;63(1):S1-44. PMID: 16581155 DOI: 10.1016/j.jhin.2006.01.001

12. Klevens RM, Edwards JR, Richards CL Jr, Horan TC, 
Gaynes RP, Pollock DA, et al. Estimating health careassociated infections and deaths in U.S. Hospitals, 2002. Public Health Rep. 2007;122(2):160-6. PMID: 17357358 DOI: $10.1177 / 003335490712200205$

13. Luyt CE, Bréchot N, Trouillet JL, Chastre J. Antibiotic stewardship in the intensive care unit. Crit Care. 2014; 18(5):480. PMID: 25405992 DOI: 10.1186/s13054-0140480-6

14. Thuong M, Arvaniti K, Ruimy R, de la Salmonière $\mathrm{P}$, Scanvic-Hameg A, Lucet JC, et al. Epidemiology of Pseudomonas aeruginosa and risk factors for carriage acquisition in an intensive care unit. J Hosp Infect. 2003; 53(4) 274-82. PMID: 12660124 DOI: 10.1053/jhin.2002.1370

15. Odland BA, Erwin ME, Jones RN. Quality control guidelines for disk diffusion and broth microdilution antimicrobial susceptibility tests with seven drugs for veterinary applications. J Clin Microbiol. 2000;38(1):453-5. PMID: 10618141

16. Hanberger H, Nilsson L, Claesson B, Kärnell A, Larsson P, Rylander M, et al. New species-related MIC breakpoints for early detection of development of resistance among Gramnegative bacteria in Swedish intensive care units. $J$ Antimicrobial Chemother. 1999;44(5):611-9. PMID: 10552977 DOI: $10.1093 / \mathrm{jac} / 44.5 .611$

17. Fahimzad A, Mamaishi S, Noorbakhsh S, Siadati A, Hashemi F, Tabatabaei S, et al. Study of antibiotics resistance in pediatric acute bacterial meningitis with E-Test method. Iran J Pediatr. 2006;16(2):149-56.

18. Sedighi I, Solgi A, Alikhani MY, Emad Momtaz H, Mihani F. Comparison of two different disk diffusion agar tests in determination of antibiotic susceptibility for E-coli isolated from urinary tract infection in pediatrics. Avicenna J Clin Med. 2010;17(1):17-20.

19. Ahmadi A, Soltanpour MM, Imani Fooladi AA. Prevalence of imipenem-resistant bacterial strains isolated from hospital and accuracy of Iranian imipenem disc product. J Gorgan Univ Med Sci. 2015;17(1):61-6.

20. Clinical and Laboratory Standards Institute. Performance standards for antimicrobial susceptibility testing; twenty-fifth informational supplement. Wayne, PA: Clinical and Laboratory Standards Institute; 2017.

21. EFSA Panel on Additives and Products or Substances used in Animal Feed (FEEDAP). Guidance on the assessment of bacterial susceptibility to antimicrobials of human and veterinary importance. EFSA J. 2012;10(6):2740. DOI: 10.2903/j.efsa.2012.2740

22. Erfani Y, Safdari R, Chobineh H, Mirsalehian A, Rasti A, Einollahi N, et al. Comparison of E. test and disk diffusion agar in detection of antibiotic susceptibility of E. coli isolated from patients with urinary tract infection in Tehran Shariati Hospital. Avicenna J Clin Med. 2008;15(2):27-31. 